\title{
Cayman Islands
}

National Cancer Institute

\section{Source}

National Cancer Institute. Cayman Islands. NCI Thesaurus. Code C16391.

An island group in the Caribbean Sea, south of Cuba and west of Jamaica. 